\title{
Are Aortic Surgery Device Technology Providers Valid or Valued Assets?
}

\author{
Cian $\operatorname{Tan}^{1}$, Mohammed Idhrees ${ }^{2}$, and Mohamad Bashir ${ }^{2}$ \\ ${ }^{1}$ Queen Mary University of London Barts and The London School of Medicine and \\ Dentistry \\ ${ }^{2}$ SRM Institutes for Medical Science Vadapalani
}

September 25, 2021

\begin{abstract}
ABSTRACT The involvement of Medical Technology (MedTech) corporations in the provision of surgical care remains a topic of debate. This relationship is especially relevant in cardiac and aortic surgery as the use of grafts, stents, prostheses, and other devices is an integral component of most procedures. Many argue that the involvement of device representatives in cardiac surgical cases is valuable - they are often experts on their product and are able to contribute their expertise in challenging cases. Yet, the potential for MedTech corporations to influence surgeons' clinical decision-making introduces a conflict-of-interest and calls into question what the 'best practice' for sales reps should be. The influence of MedTech corporations over policymaking bodies in the US, UK, and Europe also represents a major issue for transparency and is equally deserving of evaluation.
\end{abstract}

\section{Hosted file}

DeviceRepsEditorial Manuscript2.docx available at https://authorea.com/users/397612/articles/ 538792-are-aortic-surgery-device-technology-providers-valid-or-valued-assets 